\title{
A rare case of synovial sarcoma presenting as abdominal pain
}

Kelsey Pan ${ }^{1}$, Nida Waheed ${ }^{1}$, James Smith $^{1}$, and Zareen Zaidi ${ }^{1}$

${ }^{1}$ University of Florida

May 18, 2020

\begin{abstract}
Sarcomas are a rare but aggressive type of malignancy that are often diagnosed late. This case describes an atypical presentation of sarcoma manifesting as abdominal pain, which previously has not been found in literature. We highlight the importance of pursuing additional workup when clinical suspicion for malignancy arises.
\end{abstract}

\section{Hosted file}

Case-Reports-Sarcoma.docx available at https://authorea.com/users/322980/articles/452156-arare-case-of-synovial-sarcoma-presenting-as-abdominal-pain 